\title{
$(-)-[18 F]$ Flubatine: evaluation in rhesus monkeys and a report of the first fully automated radiosynthesis validated for clinical use
}

\author{
Brian G. Hockley, ${ }^{a}$ Megan N. Stewart, ${ }^{b}$ Phillip Sherman, ${ }^{\text {a }}$ Carole Quesada, ${ }^{a}$ \\ Michael R. Kilbourn, ${ }^{a}$ Roger L. Albin, ${ }^{c, d}$ and Peter J. H. Scott ${ }^{a, b *}$
}

(-)-[ ${ }^{18}$ F]Flubatine was selected for clinical imaging of $\alpha_{4} \beta_{2}$ nicotinic acetylcholine receptors because of its high affinity and appropriate kinetic profile. A fully automated synthesis of $(-)-\left[{ }^{18} \mathrm{~F}\right]$ flubatine as a sterile isotonic solution suitable for clinical use is reported, as well as the first evaluation in nonhuman primates (rhesus macaques). $(-)-\left[{ }^{18}\right.$ F]Flubatine was prepared by fluorination of the Boc-protected trimethylammonium iodide precursor with $\left[{ }^{18} \mathrm{~F}\right]$ fluoride in an automated synthesis module. Subsequent deprotection of the Boc group with 1-M HCl yielded (-)-[ $\left.{ }^{18} \mathrm{~F}\right]$ flubatine, which was purified by semi-preparative HPLC. (-)-[ ${ }^{18}$ F]Flubatine was prepared in $25 \%$ radiochemical yield (formulated for clinical use at end of synthesis, $n=3$ ), $>95 \%$ radiochemical purity, and specific activity $=4647 \mathrm{Ci} / \mathrm{mmol}(171.9 \mathrm{GBq} / \mu \mathrm{mol})$. Doses met all quality control criteria confirming their suitability for clinical use. Evaluation of $(-)-\left[{ }^{18} \mathrm{~F}\right]$ flubatine in rhesus macaques was performed with a Concorde MicroPET P4 scanner (Concorde MicroSystems, Knoxville, TN). The brain was imaged for $\mathbf{9 0}$ min, and data were reconstructed using the 3-D maximum a posteriori algorithm. Image analysis revealed higher uptake and slower washout in the thalamus than those in other areas of the brain and peak uptake at $45 \mathrm{~min}$. Injection of $2.5 \mu \mathrm{g} / \mathrm{kg}$ of nifene at 60 min initiated a slow washout of $\left[{ }^{18}\right.$ F]flubatine, with about $25 \%$ clearance from the thalamus by the end of imaging at $90 \mathrm{~min}$.

Keywords: nicotinic acetylcholine receptors; norchloro-fluoro-homoepibatidine; (-)-[ ${ }^{18}$ F]NCFHEB; positron emission tomography (PET) imaging

\section{Introduction}

Dysfunction of the cholinergic neurotransmitter system is one factor contributing to cognitive decline in neurodegenerative disorders such as Alzheimer's disease. ${ }^{1}$ Reflecting this, noninvasive positron emission tomography imaging of cholinergic brain function is an extremely active research arena. Radiopharmaceuticals that permit measurement of the vesicular acetylcholine transporter, acetylcholinesterase activity, and both muscarinic and nicotinic acetylcholine receptors (nAChRs) find widespread clinical application (for recent reviews, see Refs $2-7^{2-7}$ ). We currently evaluate acetylcholinesterase activity by using $1-\left[{ }^{11} \mathrm{C}\right]$ methylpiperidin-4-yl propionate ${ }^{8}$ and the vesicular acetylcholine transporter with $(2 R, 3 R)-5-\left[{ }^{18} \mathrm{~F}\right]$ fluoroethoxy-benzovesamicol. ${ }^{9}$ With the goal of expanding our understanding of cholinergic dysfunction in our clinical population, we were desirous of also making a radiopharmaceutical available for clinical imaging of nAChRs. Many radiopharmaceuticals for quantification of $n A C h R s$ have been reported to date (reviewed in Refs $2-7^{2-7}$ ), but we focused our attention on $\left[{ }^{18} \mathrm{~F}\right] \mathrm{A} 85380^{10-13}$ and $\left[{ }^{18} \mathrm{~F}\right]$ flubatine $\left(\left[{ }^{18} \mathrm{~F}\right] \mathrm{NCFHEB}\right){ }^{14-18}$ as they have been used to image nAChRs in a clinical setting. Ultimately, $\left[{ }^{18} \mathrm{~F}\right]$ flubatine, a radiolabeled derivative of epibatidine, was selected because it has the most practical kinetic profile (the slow kinetics of $\left[{ }^{18} \mathrm{~F}\right] \mathrm{A} 85380$ severely limit its utility for imaging cognitively impaired patients ${ }^{4,5,10}$ ).
Herein, we report a fully automated radiosynthesis of $(-)-\left[{ }^{18} \mathrm{~F}\right]$ flubatine that provides the radiopharmaceutical formulated as a sterile, isotonic solution suitable for clinical use. The original syntheses provided (+)-[ $\left[{ }^{18} \mathrm{~F}\right]$ flubatine and $(-)-\left[{ }^{18} \mathrm{~F}\right]$ flubatine in $2 \%$ radiochemical yield and utilized an ethyl carbamate-protected bromo precursor, specialized microwave synthesis equipment, iodotrimethylsilane-mediated carbamate deprotection, and two semi-preparative HPLC purifications including a chiral one as a racemic precursor was employed. ${ }^{14-16}$ This was not readily adaptable to clinical radiopharmaceutical production in our positron-emission tomography (PET) center, and so, we have built upon this initial work

${ }^{a}$ Department of Radiology, University of Michigan Medical School, Ann Arbor MI, USA

${ }^{b}$ The Interdepartmental Program in Medicinal Chemistry, The University of Michigan, Ann Arbor, MI, USA

${ }^{c}$ Geriatrics Research, Education and Clinical Center, VAAAHS, Ann Arbor, MI, USA

${ }^{d}$ Department of Neurology, The University of Michigan Medical School, Ann Arbor, MI, USA

*Correspondence to: Peter J. H. Scott, Department of Radiology, University of Michigan Medical School, Ann Arbor, MI, USA.

E-mail:pjhscott@umich.edu 
and capitalized on the enantiomerically pure Boc-protected trialkyl ammonium iodide precursor now commercially available to simplify the synthesis. We report a fully automated, high yielding radiosynthesis of (-)-[ $\left[{ }^{18} \mathrm{~F}\right]$ flubatine on a standard automated fluorine-18 synthesis module. Acid-mediated deprotection of the Boc group and purification of the product by using semipreparative HPLC with a standard C18 column make it suitable for production of clinical doses. Completion of this synthesis optimization in our laboratory coincided with reports of an extensive precursor evaluation study by Fischer and colleagues, ${ }^{19}$ which reported improved yields (up to $60 \%$ by using manual radiochemical methods although no radioactivity amounts were specified) and also concluded that the Boc-protected trialkyl ammonium iodide is the precursor of choice for synthesizing $(-)-\left[{ }^{18} \mathrm{~F}\right]$ flubatine. Finally, with the goal of expanding the repository of imaging data and the understanding of how $(-)-\left[{ }^{18} \mathrm{~F}\right]$ flubatine behaves in different species, we also report the first evaluation of (-)-[ $\left.{ }^{18} \mathrm{~F}\right]$ flubatine in nonhuman primates (rhesus macaques).

\section{Materials and methods}

\section{General considerations}

Unless otherwise stated, reagents and solvents were commercially available and used without further purification: (-)-flubatine precursor and reference standard were purchased from $A B X$ Advanced Biochemicals; potassium carbonate, sodium hydroxide, and hydrochloric acid were purchased from Sigma Aldrich; kryptofix-2.2.2, acetonitrile, and dimethyl sulfoxide (DMSO) were purchased from Acros Organics; ethanol for HPLC was purchased from Decon Laboratories, Inc.; and sodium chloride, 0.9\% United States Pharmacopeia (USP), and sodium phosphates for injection, USP, were purchased from Hospira. Other synthesis components were obtained as follows: sterile filters were obtained from Millipore, sterile product vials were purchased from Hollister-Stier, and QMA-Light Sep-paks were purchased from Waters Corporation. Sep-Paks were flushed prior to use: $10 \mathrm{~mL}$ of $\mathrm{NaHCO}_{3}-10 \mathrm{~mL}$ of deionized water-10-mL ethanol-10 $\mathrm{mL}$ of deionized water.

\section{Synthesis of $(-)-\left[{ }^{18} \mathrm{~F}\right]$ flubatine}

To prepare (-)-[ $\left.{ }^{18} \mathrm{~F}\right]$ flubatine, we configured a General Electric TRACERlab FX $_{\mathrm{FN}}$ synthesis module as previously described ${ }^{20}$ and loaded as follows: Vial 1, potassium carbonate $(3.5 \mathrm{mg})$ in deionized water $(0.5 \mathrm{~mL})$; Vial 2, kryptofix-2.2.2 (10-15 mg) in acetonitrile (1 mL); Vial 3, (-)-flubatine precursor (1 mg) in DMSO (0.6 mL); Vial 4, 1-M HCl (1 mL); Vial 5, 0.5-M NaOH (2 mL); product collection vial, $0.9 \%$ sodium chloride for injection (USP, $3.9 \mathrm{~mL}$ ) and sodium phosphates for injection (USP, $0.1 \mathrm{~mL}$ ).

$\left[{ }^{18} \mathrm{~F}\right]$ Fluoride $(\sim 800 \mathrm{mCi}$ and $29.6 \mathrm{GBq})$ was produced via the ${ }^{18} \mathrm{O}(p, n){ }^{18} \mathrm{~F}$ nuclear reaction by using a General Electric PETtrace cyclotron equipped with a high-yield fluorine-18 target. The $\left[{ }^{18} \mathrm{~F}\right]$ fluoride was delivered in a $1.5-\mathrm{mL}$ bolus of $\left[{ }^{18} \mathrm{O}\right] \mathrm{H}_{2} \mathrm{O}$ to the synthesis module and trapped on a QMA-Light Sep-Pak to remove $\left[{ }^{18} \mathrm{O}\right] \mathrm{H}_{2} \mathrm{O}$. $\left[{ }^{18} \mathrm{~F}\right] \mathrm{Fluoride}$ was then eluted into the reaction vessel by using aqueous potassium carbonate $(3.5 \mathrm{mg}$ in $0.5 \mathrm{~mL}$ of water). The solution of kryptofix-2.2.2 (10-15 mg in $1 \mathrm{~mL}$ of acetonitrile) was then added to the reaction vessel, and the $\left[{ }^{18} \mathrm{~F}\right]$ fluoride was dried by evaporating the water-acetonitrile azeotrope. Evaporation of the azeotrope was achieved by heating the reaction vessel to $80^{\circ} \mathrm{C}$ and drawing full vacuum for $4 \mathrm{~min}$. After this time, the reaction vessel was cooled to $60^{\circ} \mathrm{C}$ and subjected to both an argon stream and a vacuum draw simultaneously for another $4 \mathrm{~min}$. The solution of $(-)$ flubatine precursor $(1 \mathrm{mg})$ in DMSO $(600 \mu \mathrm{L})$ was added to the dried $\left[{ }^{18} \mathrm{~F}\right]$ fluoride, and the reaction was heated to $120^{\circ} \mathrm{C}$ with stirring for $10 \mathrm{~min}$. Subsequently, the reaction mixture was cooled to $80^{\circ} \mathrm{C}$, followed by the addition of $1-\mathrm{M} \mathrm{HCl}(1 \mathrm{~mL})$ and then maintained at $80^{\circ} \mathrm{C}$ with stirring for an additional $5 \mathrm{~min}$ to remove the Boc group. The reaction mixture was then cooled to $50^{\circ} \mathrm{C}$, quenched with $0.5-\mathrm{M} \mathrm{NaOH}$, and purified by semi-preparative HPLC (column, Phenomonex Luna C18(2) $10 \mu, 250 \times 10 \mathrm{~mm}$; mobile phase, $4 \%$ ethanol in $20-\mathrm{mM} \mathrm{NaH}_{2} \mathrm{PO}_{4} ; \mathrm{pH}, 4.0$; flow rate, $4 \mathrm{~mL} / \mathrm{min}$; and typical semi-preparative trace, Figure 1). The product peak ( $t_{\mathrm{R}} 20-25 \mathrm{~min}$ ) was collected into the product collection vial with concomitant dilution into $0.9 \%$ sodium chloride for injection, USP, and sodium phosphates for injection, USP. The final formulation was then passed through a $0.22-\mu \mathrm{m}$ filter into a



Figure 1. Typical semi-preparative HPLC trace. UV, ultraviolet; AU, absorbance unit. 
sterile dose vial and submitted for quality control testing as outlined later in the text. Typical radiochemical yields of formulated $(-)-\left[{ }^{18} \mathrm{~F}\right]$ flubatine prepared using this method are $25 \%$ at end of synthesis (EOS).

\section{Quality control of (-)-[ $\left.{ }^{18} \mathrm{~F}\right]$ flubatine}

Quality control testing of $(-)-\left[{ }^{18} \mathrm{~F}\right]$ flubatine was conducted using the guidelines outlined in the US Pharmacopeia using the standard tests previously described, ${ }^{20}$ and results are reported in Table 1. Testing included visual inspection, $\mathrm{pH}$, chemical purity and radiochemical purity $(\mathrm{RCP}$, see Analysis of Chemical Purity and Radiochemical Purity/Identity section), specific activity, residual solvent analysis, residual kryptofix analysis, sterile filter integrity, bacterial endotoxin analysis, and sterility testing.

\section{Analysis of chemical purity and radiochemical purity/identity}

Chemical and radiochemical purities/identities are analyzed using a Shimadzu LC2010 HPLC equipped with a radioactivity detector and an ultraviolet (UV) detector, and a representative analytical HPLC trace is shown (Figure 2). Radiochemical purity for doses must be $>95 \%$, and identity is confirmed by comparing the retention time of the radiolabeled product with that of the corresponding unlabeled reference standard. Column-Phenomonex Synergi Polar-RP $4 \mu, 150 \times 4.6 \mathrm{~mm}$; mobile phase $-50 \%$ acetonitrile :50\% 0.1-M acetic acid; $\mathrm{pH}, 4.5$;

Table 1. Quality control data for $(-)-\left[{ }^{18} \mathrm{~F}\right]$ flubatine (mean values reported, $n=3$ )

\begin{tabular}{lccccccccc}
$\begin{array}{l}\text { Visual } \\
\text { inspection }\end{array}$ & $\mathrm{pH}$ & $\begin{array}{c}t_{1 / 2} \\
(\mathrm{~min})\end{array}$ & $\begin{array}{c}\mathrm{RCP} \\
(\%)\end{array}$ & $\begin{array}{c}\mathrm{SA} \\
(\mathrm{Ci} / \mathrm{mmol})\end{array}$ & $\begin{array}{c}\mathrm{RSA} \mathrm{MeCN}- \\
\mathrm{DMSO}\end{array}$ & $\begin{array}{c}\mathrm{K} 222 \\
(\mu \mathrm{g} / \mathrm{mL})\end{array}$ & $\begin{array}{c}\text { Bubble } \\
\text { point }\end{array}$ & $\begin{array}{c}\text { Endotoxins } \\
(\mathrm{EU} / \mathrm{mL})\end{array}$ & \begin{tabular}{c} 
Sterility \\
\hline Pass
\end{tabular} \\
\hline 6.5 & 110 & 99.8 & 4647 & Pass & $<50$ & Pass & $<2.0$ & Pass
\end{tabular}

RCP, radiochemical purity; SA, specific activity; RSA MeCN-DMSO, Residual Solvent Analysis acetonitrile-dimethyl sulfoxide.

\section{UV Detector Response}

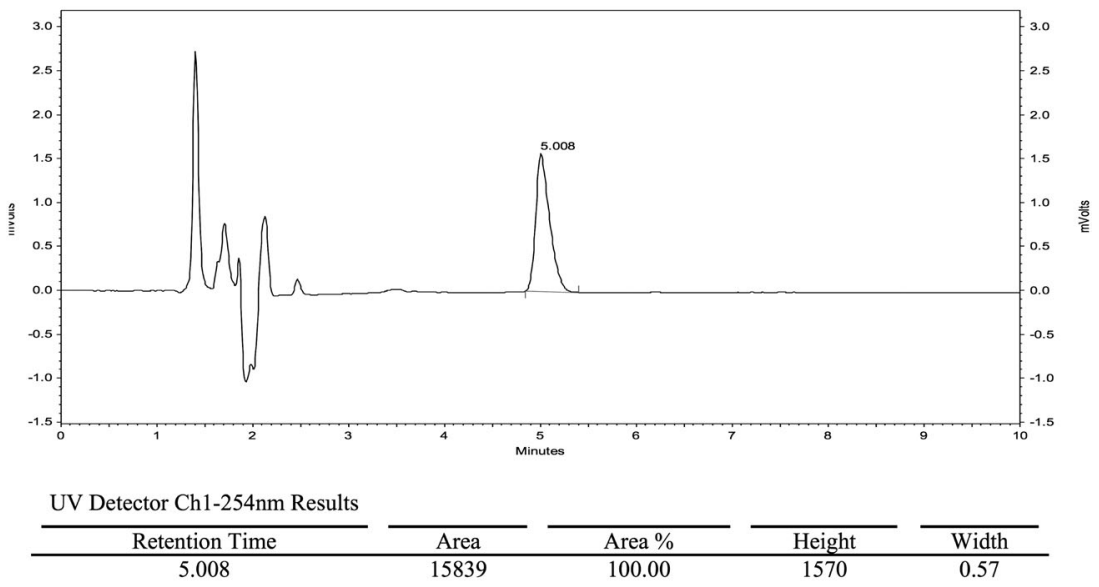

\section{Radioactivity Detector Response}

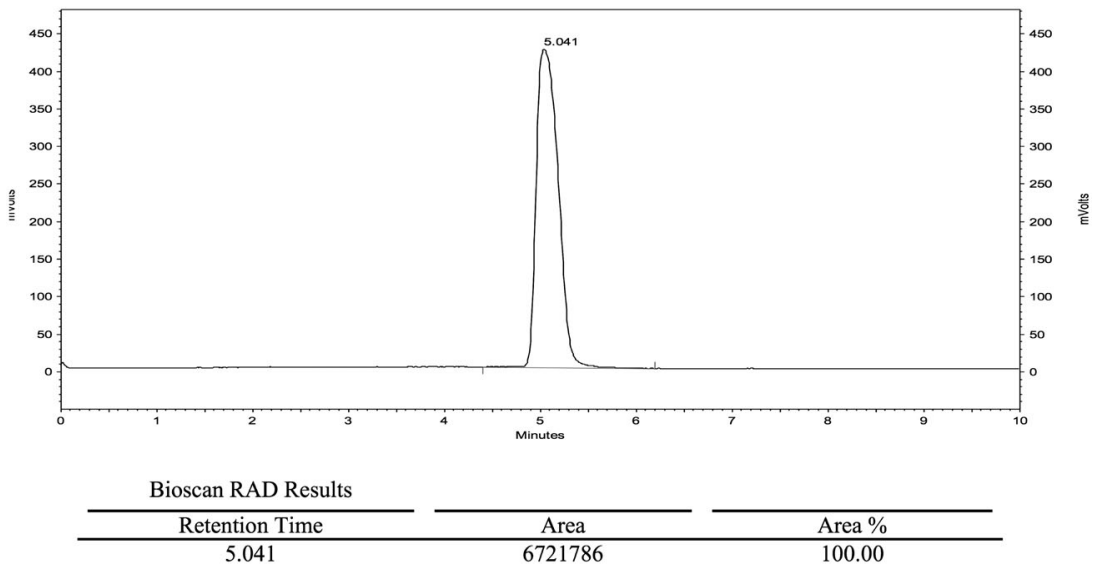

Figure 2. Typical analytical HPLC trace. UV, ultraviolet. RAD, radioactivity detector. 
flow rate, $1.0 \mathrm{~mL} / \mathrm{min}$; oven $-40^{\circ} \mathrm{C}$; UV, $254 \mathrm{~nm}$; $t_{\mathrm{R}}=5.0 \mathrm{~min}$; and capacity factor $=2.56$. $(-)-\left[{ }^{19} \mathrm{~F}\right]$ Flubatine nonradioactive reference standard was purchased from ABX Advanced Biochemicals.

\section{Primate micropositron-emission tomography imaging}

All animal studies were performed in accordance with the standards set by the University Committee on Use and Care of Animals (UCUCA) at the University of Michigan. Primate imaging studies $(n=3)$ were performed using a mature female rhesus monkey (weight $=5.8 \mathrm{~kg}$ ). The monkey was anesthetized (isoflurane), intubated, and positioned in a Concorde MicroPET P4 scanner. Following a transmission scan was the injection of the animal intravenously with (-)-[ $\left.{ }^{18} \mathrm{~F}\right]$ flubatine $(4-5 \mathrm{mCi}$ $(148-185 \mathrm{MBq})$ ) as a bolus over $1 \mathrm{~min}$. The collection of emission data was started with radiotracer injection, and the brain was imaged for $90 \mathrm{~min}(18 \times 5-\mathrm{min}$ frames). Image data were reconstructed using the $3-D$ maximum a posteriori algorithm (Figure 3). By using a summed image, regions of interest were drawn over sections of the brain (thalamus, cortex, striatum, and cerebellum), and time-radioactivity curves were calculated (Figure 4). For the displacement study, a $2.5-\mu \mathrm{g} / \mathrm{kg}$ dose of the selective $\alpha_{4} \beta_{2} \mathrm{nAChR}$ agonist nifene was injected intravenously at $60 \mathrm{~min}$ after the radiotracer injection, and scanning continued until $90 \mathrm{~min}$, and time-radioactivity curves were generated in an analogous fashion (Figure 5).

\section{Results and discussion}

\section{Synthesis of $(-)-\left[{ }^{18} \mathrm{~F}\right]$ flubatine}

The original syntheses of $(-)-\left[{ }^{18} \mathrm{~F}\right]$ flubatine reported in the literature utilized a racemic ethyl carbamate-protected bromo precursor that was reacted with $\left[{ }^{18} \mathrm{~F}\right]$ fluoride in a microwave system, and the protecting group was removed by treating with iodotrimethylsilane. Final purification by semi-preparative HPLC involved an initial chiral column to separate enantiomers and then a second HPLC to remove chemical impurities and provide $(-)-\left[{ }^{18} \mathrm{~F}\right]$ flubatine in $2 \%$ yield. ${ }^{14,16}$ This chemistry has proven suitable for the initial preclinical evaluation of the radiopharmaceutical ${ }^{14,15}$ and the first-in-man evaluation that has been recently reported. ${ }^{17,18}$ However, as we looked to make (-)-[ $\left.{ }^{18} \mathrm{~F}\right]$ flubatine available to our clinicians, we had cause to develop an entirely new synthesis more suitable for our synthesis equipment, by using the newly commercially available enantiomerically pure Boc-protected trimethylammonium salt precursor. $(-)-\left[{ }^{18} \mathrm{~F}\right]$ Flubatine was prepared according to Scheme 1 , and as outlined in Synthesis of (-)-[18F]Flubatine section. Subjecting the Boc-protected trimethylammonium iodide precursor to our standard fluorination conditions resulted in high conversion $(>95 \%)$ to Boc-protected (-)-[ $\left[{ }^{18} \mathrm{~F}\right]$ flubatine. As we wished to avoid using iodotrimethylsilane in our clinical synthesis modules, alternative strategies for removing the carbamate protecting group were evaluated. Aqueous hydrochloric acid (1 M) is our standard protocol for removal of Boc-protecting groups in fluorine-18 radiochemical reactions, and gratifyingly it worked well in this case too. Similar results were reported by Fischer and co-workers in their precursor matrix study. ${ }^{19} \mathrm{~A}$ single semipreparative HPLC yielded (-)-[ $\left.{ }^{18} \mathrm{~F}\right]$ flubatine, and the total synthesis time was about $60 \mathrm{~min}$. Three consecutive syntheses were completed to qualify the synthetic method for clinical production of $(-)-\left[{ }^{18} \mathrm{~F}\right]$ flubatine, with typical yields of formulated product of $200 \mathrm{mCi}(7.4 \mathrm{GBq})$ at EOS $(25 \%$ based upon $800 \mathrm{mCi}$ $(29.6 \mathrm{GBq})$ of $\left[{ }^{18} \mathrm{~F}\right]$ fluoride, non-decay corrected, $\left.n=3\right)$. The radiochemical purity was $>95 \%$, and specific activity was $4647 \mathrm{Ci} / \mathrm{mmol}(171.9 \mathrm{GBq} / \mu \mathrm{mol})$ at EOS. Doses of $(-)-\left[{ }^{18} \mathrm{~F}\right]$ flubatine met all of the established release criteria as summarized in Table 1 and described earlier, confirming their suitability for use in clinical PET imaging of nAChRs.

\section{Micropositron-emission tomography imaging in rhesus monkeys}

With doses of $(-)-\left[{ }^{18} \mathrm{~F}\right]$ flubatine available, we were interested in assessing the regional distribution and time-activity curves in the rhesus macaque brain. Following a transmission scan, the administration of the monkey, with $4-5 \mathrm{mCi}(148-185 \mathrm{MBq})$ of $(-)-\left[{ }^{18} \mathrm{~F}\right]$ flubatine, was performed, and it received a $90-\mathrm{min}$ dynamic PET scan $(18 \times 5$-min frames). Image data were reconstructed using the $3-D$ maximum a posteriori algorithm, and expected uptake in the thalamus, frontal cortex, and striatum, areas of the brain rich in $\alpha_{4} \beta_{2} \mathrm{nAChRs}$, was apparent (Figure 3).

By using a summed image, regions of interest were drawn over sections of the brain (thalamus, cortex, striatum, and cerebellum), and time-radioactivity curves were calculated. Uptake was normalized to injected dose and averaged for the three scans (Figure 4). Higher uptake and slower washout of $(-)-\left[{ }^{18} \mathrm{~F}\right]$ flubatine were observed in the thalamus than those in the other regions of the brain, which was expected and is consistent with previously reported data in piglets ${ }^{14,15}$ and humans. ${ }^{17,18}$ Peak uptake for the thalamus in the rhesus monkeys ( $45 \mathrm{~min}$ ) was found to be faster than the reported peak uptake for piglets $(80 \mathrm{~min})$. Although no obvious explanation

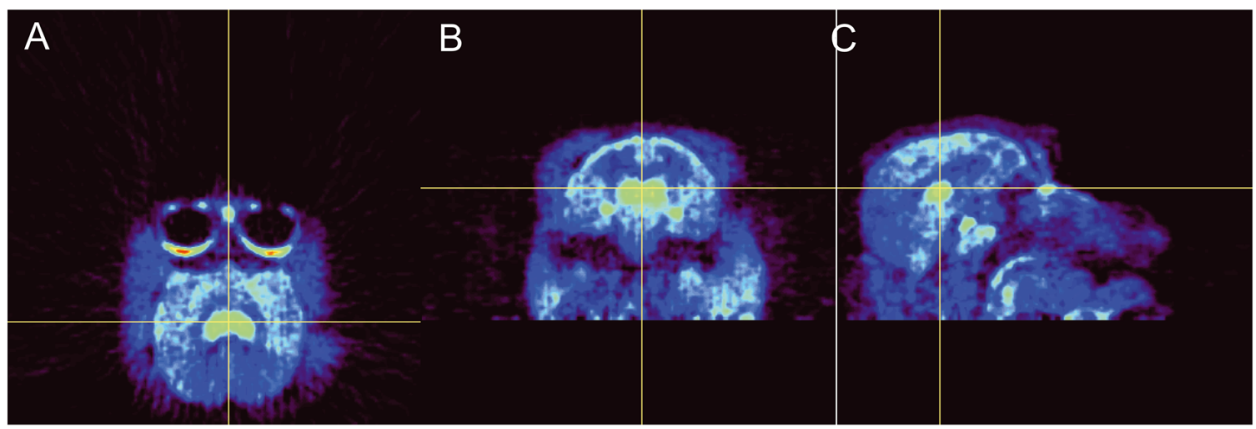

Figure 3. Typical summed primate microPET images acquired with (-)-[ $\left.{ }^{18} \mathrm{~F}\right]$ flubatine. The monkey was administered with $4-5 \mathrm{mCi}(148-185 \mathrm{MBq})$ of $(-)-\left[{ }^{18} \mathrm{~F}\right]$ flubatine and received a 90 -min dynamic PET scan $(18 \times 5$-min frames). Image data were reconstructed using the 3-D maximum a posteriori algorithm ( , transverse; $B$, coronal; and C, sagittal). 


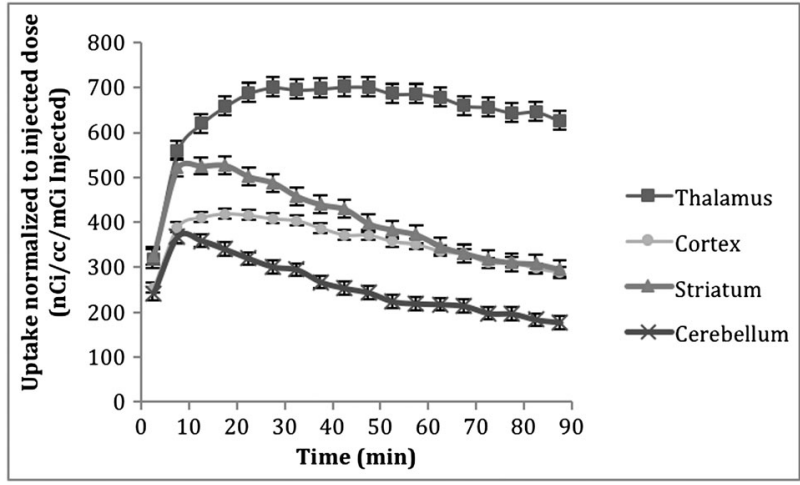

Figure 4. Brain tissue time-radioactivity curves (uptake normalized to injected dose and averaged for three scans). Data are mean \pm standard error.

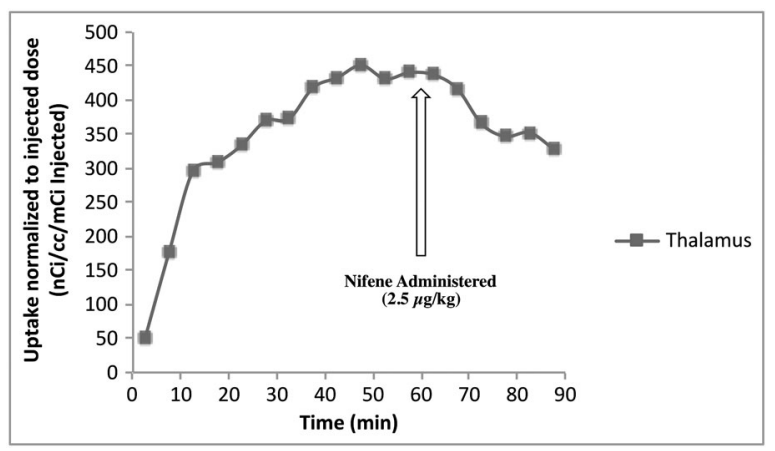

Figure 5. Brain tissue time-radioactivity curves for displacement experiment with unlabeled nifene $(2.5 \mu \mathrm{g} / \mathrm{kg}$, intravenous, uptake normalized to injected dose, $n=1)$.

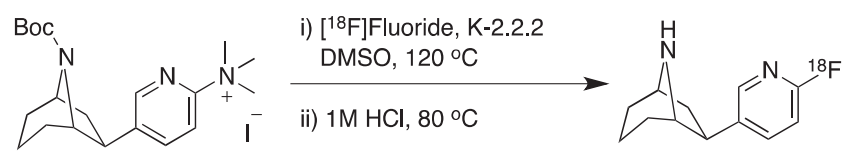

Scheme 1. Synthesis of (-)-[ ${ }^{18}$ F]flubatine. DMSO, dimethyl sulfoxide.

exists for this species difference, it does lend support to the recent suggestion that $(-)-\left[{ }^{18} \mathrm{~F}\right]$ flubatine kinetics will allow all kinetic parameters to be estimated from clinical PET data acquired over only 90 min. ${ }^{17,18}$ Finally, the injection of a $2.5-\mu \mathrm{g} / \mathrm{kg}$ dose of the selective $\alpha_{4} \beta_{2} \mathrm{nAChR}$ agonist nifene ${ }^{21}$ at $60 \mathrm{~min}$ initiated a slow washout of $\left[{ }^{18} \mathrm{~F}\right]$ flubatine from the thalamus, with about $25 \%$ clearance by the end of the imaging study at $90 \mathrm{~min}$ (Figure 5).

\section{Conclusion}

In conclusion, a fully automated radiosynthesis of $(-)-\left[{ }^{18} \mathrm{~F}\right]$ flubatine has been established. Doses met all quality control criteria, confirming their suitability for application in clinical imaging. Evaluation of $(-)-\left[{ }^{18} \mathrm{~F}\right]$ flubatine in rhesus macaques revealed higher uptake and slower washout in the thalamus than those in the other areas of the brain, and the time-activity curves confirm that $(-)-\left[{ }^{18} \mathrm{~F}\right]$ flubatine has kinetics that will simplify PET imaging of $\alpha_{4} \beta_{2} \mathrm{nAChRs}$ in a clinical setting.

\section{Acknowledgements}

Financial support for this research from the University of Michigan Medical School (Department of Radiology and the Office of the Dean) and the University of Michigan College of Pharmacy is gratefully acknowledged.

\section{Conflict of Interest}

The authors report no conflict of interest.

\section{References}

[1] P. T. Francis, A. M. Palmer, M. Snape, G. K. Wilcock, J. Neurol. Neurosurg. Psychiatry 1999, 66, 137.

[2] W. Sihver, B. Långström, A. Nordberg, Acta Neurol. Scand. 2000, 176 (Supplement), 27.

[3] N. D. Volkow, Y-S. Ding, J. S. Fowler, S. J. Gatley, Biol. Psychiatry 2001, 49, 211.

[4] N. I. Bohnen, K. A. Frey, Mol. Imaging Biol. 2007, 9, 243.

[5] A. G. Horti, V. L. Villemagne, Curr. Pharm. Des. 2006, 12, 3877.

[6] A. G. Horti, Y. Gao, H. Kuwabara, R. F. Dannals, Life Sci. 2010, 86, 575.

[7] A. G. Horti, D. F. Wong, PET Clin. 2009, 4, 89.

[8] S. E. Snyder, N. Gunupudi, P. S. Sherman, E. R. Butch, M. B. Skaddan, M. R. Kilbourn, R. A. Koeppe, D. E. Kuhl, J. Cerebral Blood Flow Metab. 2001, 21, 132.

[9] M. Petrou, R. A. Koeppe, P. J. H. Scott, N. I. Bohnen, M. R. Kilbourn, K. A. Frey, J. Nucl. Med. 2012, 53(Suppl. 1), 89P.

[10] J. D. Gallezot, M. Bottlaender, M. C. Gregoire, D. Roumenov, J. R. Deverre, C. Coulon, M. Ottaviani, F. Dolle, A. Syrota, H. Valette, J. Nucl. Med. 2005, 46, 240.

[11] A. G. Horti, U. Scheffel, A. O. Koren, H. T. Ravert, W. B. Mathews, J. L. Musachio, P. A. Finley, E. D. London, R. F. Dannals, Nucl. Med. Biol. $1998,25,599$.

[12] A. S. Kimes, A. G. Horti, E. D. London, S. I. Chefer, C. Contoreggi, M. Ernst, P. Friello, A. O. Koren, V. Kurian, J. A. Matochik, O. Pavlova, D. P. Vaupel, A. G. Mukhin, FASEB J. 2003, 17, 1331.

[13] M. Bottlaender, H. Valette, D. Roumenov, F. Dolle, C. Coulon, M. Ottaviani, F. Hinnen, M. Ricard, J. Nucl. Med. 2003, 44, 596.

[14] W. Deuther-Conrad, J. T. Patt, P. R. Lockman, D. D. Allen, M. Patt, A. Schildan, V. Ganapathy, J. Steinbach, O. Sabri, P. Brust, Eur. Neuropsychopharmacol. 2008, 18, 222.

[15] P. Brust, J. T. Patt, W. Deuther-Conrad, G. Becker, M. Patt, A. Schildan, D. Sorger, K. Kendziorra, P. Meyer, J. Steinbach, O. Sabri, Synapse 2008, 62, 205.

[16] J. T. Patt, W. Deuther-Conrad, K. Wohlfarth, D. Feuerbach, P. Brust, J. Steinbach, J. Label. Compd. Radiopharm. 2003, 46, S168.

[17] O. Sabri, S. Wilke, S. Graef, G. Becker, S. Hesse, P. Schönknecht, G. Wagenknecht, A. Höpping, J. Steibach, P. Brust, J. Cerebral Blood Flow Metab. 2012, 32(Suppl. 1), S55.

[18] G. Becker, S. Wilke, P. Schönknecht, M. Patt, J. Luthardt, S. Hesse, G. Wagenknecht, A. Höpping, P. Brust, O. Sabri, J. Cerebral Blood Flow Metab. 2012, 32(Suppl. 1), S172.

[19] S. Fischer, A. Hiller, R. Smits, A. Höpping, U. Funke, B. Wenzel, P. Cumming, O. Sabri, J. Steinbach, P. Brust, Appl. Radiat. Isot. 2013, $74,128$.

[20] X. Shao, B. G. Hockley, L. J. M. Tluczek, R. Hoareau, P. J. H. Scott, J. Label. Compd. Radiopharm. 2011, 54, 292.

[21] A. T. Hilmer, D. W. Wooten, M. S. Slesarev, E. O. Ahlers, T. E. Barnhart, D. Murali, M. L. Schneider, J. Mukherjee, B. T. Christian, J. Nucl. Med. 2012, 53, 1471. 